\title{
Utility of Near-Infrared Reflectance Spectroscopy to Predict Nutrient Composition and In Vitro Digestibility of Total Mixed Rations
}

\author{
R. L. Mentink, ${ }^{\star}$ P. C. Hoffman, $\dagger^{1}$ and L. M. Bauman \\ ${ }^{*}$ School of Veterinary Medicine, and \\ †Department of Dairy Science, and \\ ‡Department of Soil Science, University of Wisconsin, Madison 53706
}

\section{ABSTRACT}

Total mixed ration $(\mathrm{TMR})$ samples $(\mathrm{n}=110)$ were analyzed for dry matter (DM), crude protein (CP), soluble CP, neutral detergent fiber (NDF), NDF CP, starch, ash, fat, total ethanol-soluble carbohydrate, and nonfiber carbohydrate (NFC). Rapidly and slowly degraded and undegraded in situ CP fractions and in vitro DM, organic matter, and NDF digestibility were determined on each TMR. The TMR were scanned using near-infrared reflectance spectroscopy (NIRS); spectra were retained with NIRS calibration and cross-validation statistics were determined using partial least squares regression methods. The CP, NDF, starch, in vitro DM, and in vitro indigestible NDF contents of TMR were predicted by NIRS with good degrees $\left(R^{2}>0.85\right)$ of accuracy with proportionally low standard errors of prediction. Moderate utility of NIRS to predict the NFC $\left(R^{2}=0.83\right)$ and fat content $\left(R^{2}=0.81\right)$ of TMR was observed. Rapidly, slowly, and undegraded in situ CP fractions in TMR were not well predicted by NIRS. Similarly, soluble CP, NDF CP, total ethanol-soluble carbohydrate, and in vitro NDF digestibility (\% of NDF) were not well predicted by NIRS. Ratios of nutrient range to reference laboratory method error were calculated and found to be positively related $\left(R^{2}=0.84\right)$ to NIRS predictability of a given TMR nutrient, suggesting some laboratory procedures were not precise enough to yield suitable NIRS predictions. Data suggest that NIRS has utility to predict basic nutrients such as CP, NDF, starch, NFC, and fat in TMR. However, difficulty was observed using NIRS in predicting key biological nutrients in TMR such as in situ CP fractions and in vitro NDF digestibility. Difficulty of NIRS in predicting these nutrients is related to the level of reference method error in relationship to the range of nutrient values in TMR, but other sources of prediction error may exist.

Received July 12, 2005.

Accepted January 4, 2006

${ }^{1}$ Corresponding author: pchoffma@facstaff.wisc.edu
Key words: total mixed ration, near-infrared spectroscopy, in vitro, in situ

\section{INTRODUCTION}

An informal web-based survey of a number of feed and forage testing laboratories serving the US dairy industry indicated that 7 of 10 laboratories using nearinfrared reflectance spectroscopy (NIRS) offer NIRS analysis for TMR fed to dairy cows. In general, NIRS prediction of nutrients in TMR by commercial forage testing laboratories is confined to nutrients such as CP, $\mathrm{NDF}, \mathrm{ADF}$, and fat. Since its inception in the agricultural industry, one often-quoted potential of NIRS is to measure nutrients in total diets in combination with direct or indirect measures of animal performance (Shenk and Westerhaus, 1994). However, research, university extension, or industry efforts to build NIRS systems to directly predict dietary nutrients in mixed diets in combination with direct or indirect measures of animal response have been limited. The utility of NIRS in this regard has, however, been demonstrated to be feasible. In animals fed forages, Norris et al. (1976) demonstrated that direct measures of performance, such as in vivo DM digestion and DM intake, could be predicted from NIRS spectra. Aufrere and MichaletDoreau (1988) observed that NIRS could be used to predict in vitro DM digestibility (IVDMD) of forages, which is an indirect measure of animal performance. In mixed diets, Almendingen et al. (2000) demonstrated that $\mathrm{CP}$ and fat content of homogenized human diets could be accurately predicted by NIRS. Likewise, White and Rouvinen-Watt (2004) developed robust NIRS equations to predict the DM, CP and fat content of mixed diets for mink.

At present, the potential of NIRS to predict nutrient content and direct or indirect measures of animal performance in TMR has not been investigated. It was the objective of this study to explore the utility of NIRS to predict nutrient content in combination with indirect measures of animal performance such as in vitro digestible OM (IVdOM), in vitro NDF digestibility 
(IVNDFD), and in situ CP fractions in TMR commonly fed to lactating dairy cattle.

\section{MATERIALS AND METHODS}

One hundred ten TMR were randomly selected from a pool of 1,002 TMR samples submitted for routine analysis to the Marshfield Soil and Forage Analysis Laboratory (Marshfield, WI). Samples were mixed, divided into 2 equal subsamples, and dried at $55^{\circ} \mathrm{C}$ for $48 \mathrm{~h}$. One dried subsample was then milled through a Wiley mill (Arthur H. Thomas Co., Philadelphia, PA) fit with a 1-mm screen and saved for nutrient analysis. The remaining dried subsample was milled through a Wiley mill fit with a 4-mm screen as described by Nocek (1988) and saved for in situ analysis. Residual DM was determined on 1-mm ground samples by drying at $105^{\circ} \mathrm{C}$ for $3 \mathrm{~h}$. The TMR were evaluated for $\mathrm{CP}$ and ash by AOAC (1990) procedures. Crude fat was determined by extraction with petroleum ether following acid treatment (AOAC, 1990), starch by the procedures of Ehrman (1996), soluble CP by the method of Krishnamoorthy et al.(1983), and total ethanol-soluble carbohydrates (TESC) by the procedures of Hall et al. (1999). The NDF contents of TMR were determined by the procedures of Goering and Van Soest (1970), with modifications by Mertens (1992). The NDF residues were evaluated for CP using AOAC (1990) procedures, resulting in NDF CP determinations. An estimate of NFC content of TMR was determined by the formula NFC = $100-[\mathrm{NDF}+\mathrm{CP}+\mathrm{ash}+$ fat $-\mathrm{NDF} \mathrm{CP}](\mathrm{NRC}, 2001)$. The IVDMD, IVdOM, in vitro digestible NDF (IVdNDF), and IVNDFD (\% of NDF) were determined by the procedures of Goering and Van Soest (1970). Basic in vitro procedures consisted of incubating a 0.5$\mathrm{g}$ dried, ground TMR sample in a $\mathrm{CO}_{2}$ back-pressured 125-mL Erlenmeyer flask containing rumen fluid, buffer medium, and macromineral and micromineral solution (Goering and Van Soest, 1970) for $48 \mathrm{~h}$ in a water bath held at $39^{\circ} \mathrm{C}$. Rumen fluid was harvested from a nonlactating dairy cow fit with a ruminal cannula fed a diet containing 59\% alfalfa-grass silage, $40 \%$ corn silage, with the remainder consisting of vitamin and mineral supplements. Rumen fluid was held at $39^{\circ} \mathrm{C}$ in $\mathrm{CO}_{2}$-gassed vessels, mixed in a $\mathrm{CO}_{2}$-gassed blender, and strained through 3 layers of cheesecloth before injection into the incubation flask. Critical conditions were adhered to in order to maximize IVdNDF as defined by Grant and Weidner (1992) and Grant and Mertens (1992). The 48-h in vitro incubations were terminated by an NDF determination (Goering and Van Soest, 1970; Mertens, 1992) yielding indigestible (id) NDF (IVidNDF). The IVdNDF contents of TMR were determined as the difference between the original NDF and idNDF contents. The IVNDFD (\% of NDF) and IVdOM were also determined for each TMR from the same assay by standard calculations (Goering and Van Soest, 1970).

An exploratory in situ evaluation was conducted to ascertain whether an NIRS utility existed for determining in situ CP fractions of TMR. Duplicate Dacron bags $(18 \times 9 \mathrm{~cm} ; 52 \mu \mathrm{m}$ pore size $)$ were filled with a 5 -g sample of dried TMR. Zero-hour bags were soaked in tepid water for $0.5 \mathrm{~h}$ to assess in situ rapidly degradable CP fraction (A). Zero-hour bags were washed according to the procedures of Cherney et al. (1990), dried at $55^{\circ} \mathrm{C}$ for $48 \mathrm{~h}$, weighed, and the remaining $\mathrm{DM}$ and $\mathrm{CP}$ determined by aforementioned procedures. To evaluate in situ undegraded CP fractions (C), duplicate sample bags for each TMR were placed in the ventral rumen of 2 ruminally cannulated nonlactating dairy cows fed an all-forage diet (45\% corn silage, $55 \%$ alfalfa silage) and supplemental minerals. Bags were incubated for $72 \mathrm{~h}$, removed, and immediately immersed in ice water to stop microbial activity. Bags were washed and DM, residual DM, and CP were determined by aforementioned procedures with microbial protein contamination estimated by the procedures of Brehm et al. (1997). The in situ slowly degraded CP fraction $(\mathbf{B})$ was calculated by difference: $\mathrm{B}=$ Total $\mathrm{CP}-(\mathrm{A}+\mathrm{C})$. All in situ CP fractions were calculated and expressed as a percentage of $\mathrm{CP}$ on a $\mathrm{DM}$ basis.

A subsample of the 1-mm dried, ground TMR was reground through a Udy mill (Udy Corp., Boulder, CO) with a 1-mm screen. The reground TMR samples were then packed into cylindrical sample holders equipped with a quartz window and scanned between 400 and $2,498 \mathrm{~nm}$ in duplicate according to the procedures of Marten et al. (1983) on a near-infrared reflectance spectrophotometer (model 6500; FOSS-NIR System, Silver Spring, MD) fit with a spinning cup holder. All TMR samples included $\mathrm{CP}$, soluble $\mathrm{CP}$, NDF, NDF CP, fat, ash, starch, NFC, TESC, IVdNDF, IVdOM, IVDMD, IVidNDF, IVNDFD (\% of NDF), and in situ A, B, and C CP fractions for calibration development. Calibrations for the aforementioned nutrients were computed using partial least squares regression methods, exploring different math transformations and different numbers of terms in the models. An optimum number of partial least squares terms was determined through maximizing coefficients of determination and minimizing standard errors of calibration (Shenk and Westerhaus, 1991a). Calibration performance was evaluated using cross validation (Shenk and Westerhaus, 1991b) in which prediction error was evaluated by dividing the calibration samples into subsets $(n=4)$ with one subset reserved for validation and the remaining subsets used for calibration. Cross validation was repeated until all 
Table 1. Summary statistics of nutrient composition of experimental TMR ${ }^{1}$

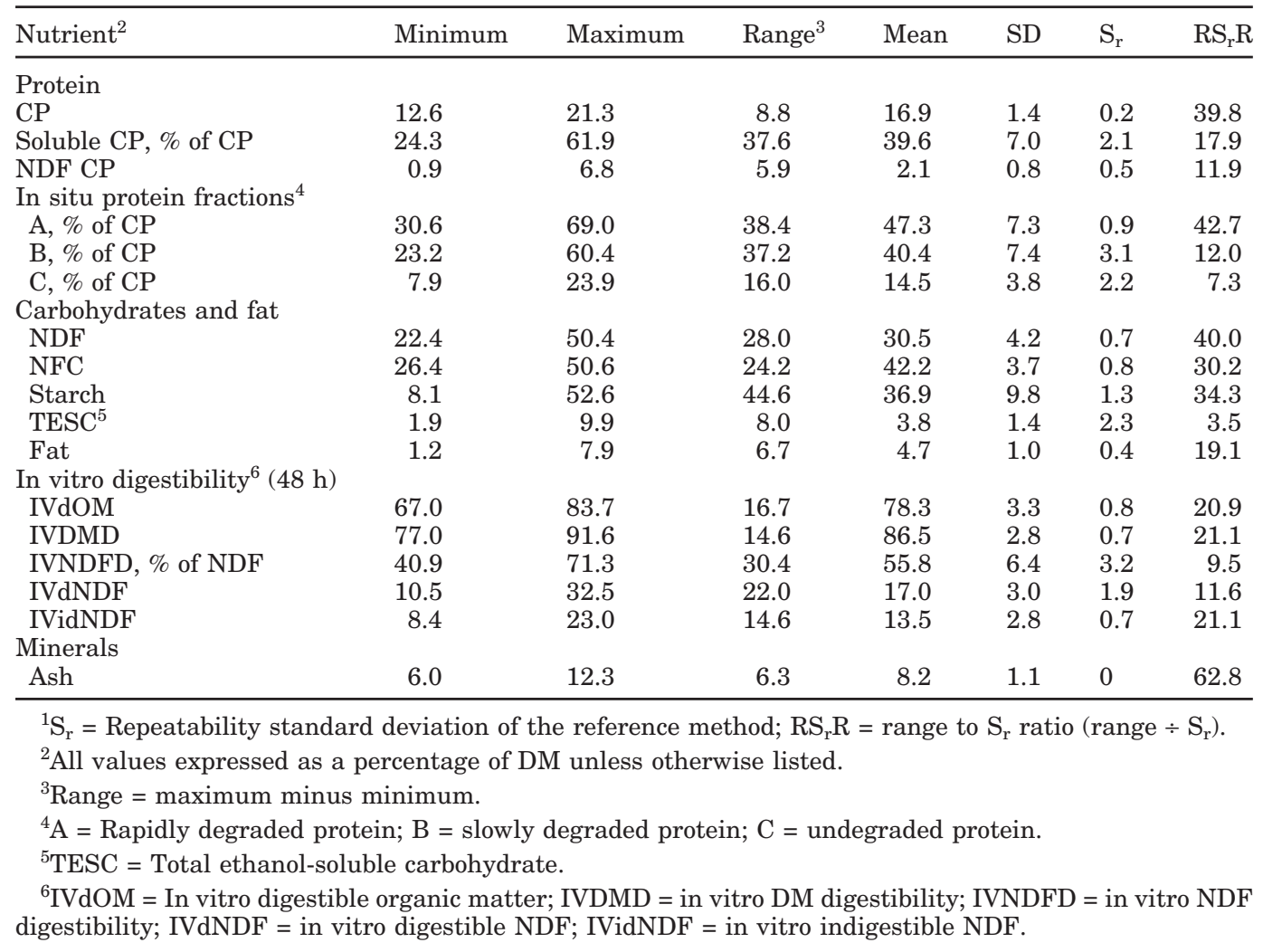

subsets were used for validation once. Strength of calibration performance was based on the cross-validation coefficient of determination $\left(\mathrm{R}^{2}\right)$, the standard error of performance (SEP) corrected for bias, and the mean bias. The repeatability standard deviation $\left(\mathbf{S}_{\mathbf{r}}\right)$ of the reference method (laboratory procedure) and range to $\mathrm{S}_{\mathrm{r}}$ ratio $\left(\mathbf{R S}_{\mathbf{r}} \mathbf{R}\right)$ were calculated to provide calibration performance inferences (Williams, 1987). The $\mathrm{S}_{\mathrm{r}}$ provides inference to unavoidable error introduced to NIRS calibration due to normal reference method laboratory errors. The $\mathrm{RS}_{\mathrm{r}} \mathrm{R}$ provides inference to laboratory error in reference to the overage range of values for a given nutrient. In general, lower $\mathrm{S}_{\mathrm{r}}$ indicates a more precise laboratory measurement and, when in the presence of a wide range of values for the nutrient, yields a high $\mathrm{RS}_{\mathrm{r}} \mathrm{R}$ value, which increases the probability of successful NIRS calibration and performance (Williams, 1987).

\section{RESULTS}

Nutrient composition of TMR and reference method errors are presented in Table 1. Based on minimum, maximum, mean, and standard deviation values, a robust database of TMR was developed to conduct NIRS determinations. Specifically, CP ranged from 12.6 to $21.3 \%$ of DM and NDF from 22.3 to $50.4 \%$ of DM in the
TMR. Likewise, the IVdOM content of TMR ranged from 67.0 to $83.7 \%$ of $\mathrm{DM}$, indicating that a wide digestibility potential existed in the TMR data set. These data, as well as data for other chemical and biological nutrients presented in Table 1, indicated that a wide range of TMR nutrient contents and indirect measures of animal performance were available to test the utility of NIRS prediction Calibration and cross-validation statistics of nutrients in TMR are presented in Table 2. The CP, NDF, starch, IVDMD and IVidNDF contents of TMR were predicted by NIRS with good degrees $\left(\mathrm{R}^{2}\right.$ $>0.85$ ) of accuracy, with proportionally acceptable SEP. The utility of NIRS to predict CP and NDF contents of forages and other feeds is well documented (Shenk and Westerhaus, 1994; Hoffman et al., 1999). Similarly, NIRS has been demonstrated to accurately predict starch content of corn silage (Barriere et al., 2004). In a recent study (Lundberg et al., 2004), good utility of NIRS was observed in predicting the IVdOM content of legume-grass forage and corn silage, which is similar to the observations of NIRS predictions of IVDMD and its reciprocal IVidNDF in this study. Also, the same relative level of efficiency of predicting IVdOM in TMR $\left(\mathrm{R}^{2}=0.80\right)$ was observed as previously seen with legume-grass forages $\left(\mathrm{R}^{2}=0.82\right.$; Lundberg et al., 2004). Likewise, moderate utility of predicting the $\mathrm{NFC}\left(\mathrm{R}^{2}=\right.$ 
Table 2. Calibration and cross-validation statistics for near-infrared spectroscopy analysis of nutrients in TMR

\begin{tabular}{|c|c|c|c|c|c|c|}
\hline \multirow[b]{2}{*}{ Nutrient $^{2}$} & \multicolumn{3}{|c|}{ Calibration $^{1}$} & \multirow[b]{2}{*}{$\mathrm{R}^{2}$} & \multicolumn{2}{|c|}{ Cross-validation } \\
\hline & Transformation & PLS Terms & SEC & & $\mathrm{R}^{2}$ & $\mathrm{SEP}^{3}$ \\
\hline \multicolumn{7}{|l|}{ Protein } \\
\hline $\mathrm{CP}$ & $2,4,4,1$ & 9 & 0.38 & 0.92 & 0.87 & 0.48 \\
\hline Soluble CP, \% of CP & $2,4,4,1$ & 8 & 3.09 & 0.78 & 0.70 & 3.62 \\
\hline NDF CP & $2,10,10,1$ & 9 & 0.43 & 0.52 & 0.44 & 0.46 \\
\hline \multicolumn{7}{|c|}{ In situ protein fractions ${ }^{4}$ : } \\
\hline $\mathrm{A}, \%$ of $\mathrm{CP}$ & $1,2,2,1$ & 8 & 4.31 & 0.62 & 0.47 & 5.10 \\
\hline $\mathrm{B}, \%$ of $\mathrm{CP}$ & $2,4,4,1$ & 7 & 4.32 & 0.68 & 0.54 & 5.16 \\
\hline $\mathrm{C}, \%$ of $\mathrm{CP}$ & $3,10,10,1$ & 10 & 1.57 & 0.70 & 0.63 & 1.74 \\
\hline \multicolumn{7}{|l|}{ Carbohydrates and fat } \\
\hline $\mathrm{NDF}$ & $3,4,4,1$ & 7 & 1.06 & 0.94 & 0.90 & 1.32 \\
\hline $\mathrm{NFC}$ & $3,4,4,1$ & 7 & 1.20 & 0.90 & 0.83 & 1.55 \\
\hline Starch & $2,4,4,1$ & 9 & 2.10 & 0.95 & 0.89 & 3.16 \\
\hline TESC $^{5}$ & $3,4,4,1$ & 9 & 0.40 & 0.89 & 0.61 & 0.75 \\
\hline Fat & $2,10,10,1$ & 9 & 0.36 & 0.85 & 0.81 & 0.40 \\
\hline \multicolumn{7}{|c|}{ In vitro digestibility ${ }^{6}(48 \mathrm{~h})$} \\
\hline IVdOM & $2,4,4,1$ & 8 & 1.21 & 0.86 & 0.80 & 1.44 \\
\hline IVDMD & $3,10,10,1$ & 9 & 0.97 & 0.88 & 0.85 & 1.07 \\
\hline IVNDFD, $\%$ of NDF & $2,4,4,1$ & 9 & 3.18 & 0.72 & 0.59 & 3.81 \\
\hline IVdNDF & $2,4,4,1$ & 8 & 1.37 & 0.75 & 0.62 & 1.69 \\
\hline IVidNDF & $3,10,10,1$ & 9 & 0.97 & 0.88 & 0.85 & 1.07 \\
\hline \multicolumn{7}{|l|}{ Minerals } \\
\hline Ash & $2,4,4,1$ & 10 & 0.35 & 0.88 & 0.77 & 0.49 \\
\hline
\end{tabular}

${ }^{1}$ PLS = Partial least squares; SEC = standard error of calibration. Transformation values equal order of derivative function, segment length (nm), segment length $(\mathrm{nm})$ of first smoothing, and segment length (nm) of second smoothing.

${ }^{2}$ All values expressed as a percentage of DM unless otherwise listed.

${ }^{3} \mathrm{SEP}=$ Standard error of prediction.

${ }^{4} \mathrm{~A}=$ Rapidly degraded protein; $\mathrm{B}=$ slowly degraded protein; $\mathrm{C}=$ undegraded protein.

${ }^{5}$ TESC $=$ Total ethanol-soluble carbohydrate.

${ }^{6} \mathrm{IVdOM}=$ In vitro digestible organic matter; IVDMD = in vitro DM digestibility; IVNDFD = in vitro NDF digestibility; IVdNDF = in vitro digestible NDF; IVidNDF = in vitro indigestible NDF.

$0.83, \mathrm{SEP}=1.55 \%$ of $\mathrm{DM})$ and fat content $\left(\mathrm{R}^{2}=0.81\right.$, SEP $=0.40 \%$ of DM) of TMR was observed using NIRS. Utility of NIRS to predict fat content of homogenized human diets (Almendingen et al., 2000) has been demonstrated; however, no literature references were found on the utility of NIRS to predict the NFC content of mixed human or animal diets.

Utility of predicting soluble CP, NDF CP, in situ A, $\mathrm{B}$, and C CP fractions, TESC, IVNDFD, IVdNDF, and ash with NIRS was less successful with all coefficients of determination being less than 0.77 . In previous experiments in this laboratory (Hoffman et al., 1999; Lundberg et al., 2004), NIRS prediction of soluble CP, and NDF CP was problematic in homogeneous forages. Similarly, Marten and Linn (1989) observed low predictability $\left(\mathrm{R}^{2}=0.59\right)$ of ADF CP using NIRS. Because assays such as soluble $\mathrm{CP}, \mathrm{NDF} \mathrm{CP}$, and $\mathrm{ADF} \mathrm{CP}$ are 2 -stage assays, there is a likelihood of higher laboratory error. Therefore, accurate NIRS predictions of these nutrients in TMR or other feeds would logically be more problematic. In situ A, B, and C CP fractions in TMR were poorly predicted by NIRS with low coefficients of determination $\left(\mathrm{R}^{2}<0.63\right)$ and, in the case of in situ fractions $\mathrm{A}$ and $\mathrm{B}$, with high $\mathrm{SEP}(>5.10 \%$ of $\mathrm{CP})$. These observations are in contrast to our previous work (Hoffman et al., 1999; Dorshorst and Hoffman, 2000) in which utility of predicting in situ A, B, and C CP fractions in legume-grass hays and silages was observed. The differences between this study and our previous work in predicting in situ protein fractions via NIRS may be related to in situ technique. Nocek (1988) warned that using in situ techniques on concentrate feeds was problematic due to excessive physical leakage of fine material out of the bags. Because TMR are heterogeneous and contain grains, protein supplements or by-product feeds of variable particle size, physical leakage of protein associated with small particles from in situ bags would be misrepresented as in situ CP fraction A. Likewise, the in situ B CP fraction would be misrepresented because it is determined as the net difference between the in situ A and C CP fractions. In our previous work (Hoffman et al., 1999; Dorshorst and Hoffman, 2000) in situ CP fractions and subsequent NIRS predictions were done on forages, which are more homogenous conducive to in situ analysis (Nocek, 1988). 
Similar to in situ CP fractions, the TESC content of TMR was not well predicted by NIRS $\left(\mathrm{R}^{2}=0.61\right.$, SEP $=$ $1.38 \%$ of DM). Narra et al. (2005) successfully predicted mono- and polysaccharide contents of turf grasses using NIRS, indicating prediction of TESC via NIRS should have been feasible. Our observed difficulties in predicting TESC content of TMR using NIRS were likely related to laboratory error associated with the TESC determination. The $\mathrm{S}_{\mathrm{r}}$ of TESC determination was 2.3 percentage units with a range of TESC in TMR of only 8.0 percentage units (Table 1). Williams (1987) warned that accurate NIRS predictions were unlikely when laboratory error is disproportional to the range of the nutrient. In short, precision of the TESC procedure as conducted in our laboratory in the presence of a narrow range of TESC values in TMR was likely the limiting factor in achieving an accurate NIRS prediction of TESC. Similarly, IVNDFD (\% of NDF) and IVdNDF (\% of DM) contents of TMR were not well predicted by NIRS. Jung et al. (1998) successfully predicted IVdNDF in corn stalks, demonstrating the utility of NIRS prediction of NDF digestibility. Inadequate prediction of these nutrients by NIRS in our study was likely the result of similar and aforementioned problems associated with reference method error in relationship to the range of IVdNDF in TMR samples. As with NDF CP, IVNDFD and IVdNDF are dual laboratory procedures, and relatively high $\mathrm{S}_{\mathrm{r}}$ were observed at $3.2 \%$ of NDF and $1.9 \%$ of DM, respectively (Table 1). Precision of the reference method with respect to the range of nutrient values in the TMR were most likely attributed to the inability of NIRS to predict these nutrients in TMR. We also observed difficulty in predicting IVNDFD of corn silage and legume silages using NIRS in a previous study (Lundberg et al., 2004).

\section{DISCUSSION}

With any trial or evaluation using NIRS, success or failure to predict a given nutrient is most often expressed as the sole responsibility of NIRS to perform the desired prediction. Successful prediction of a nutrient by NIRS is, however, a dual function of the precision of the reference laboratory method in combination with the specificity of NIRS to distinguish organic molecular bonds directly associated with the nutrient in question (Shenk and Westerhaus, 1994). Hruschka (1987) eloquently defined the 2 principal sources of NIRS determination error to be sampling and laboratory reference method error. In this study, reasonably good utility of NIRS to predict the CP, NDF, NFC, starch, fat, IVdOM, and the IVDMD content of TMR was observed. Other nutrients evaluated in TMR were not as well predicted by NIRS. These observations appear to be similar to

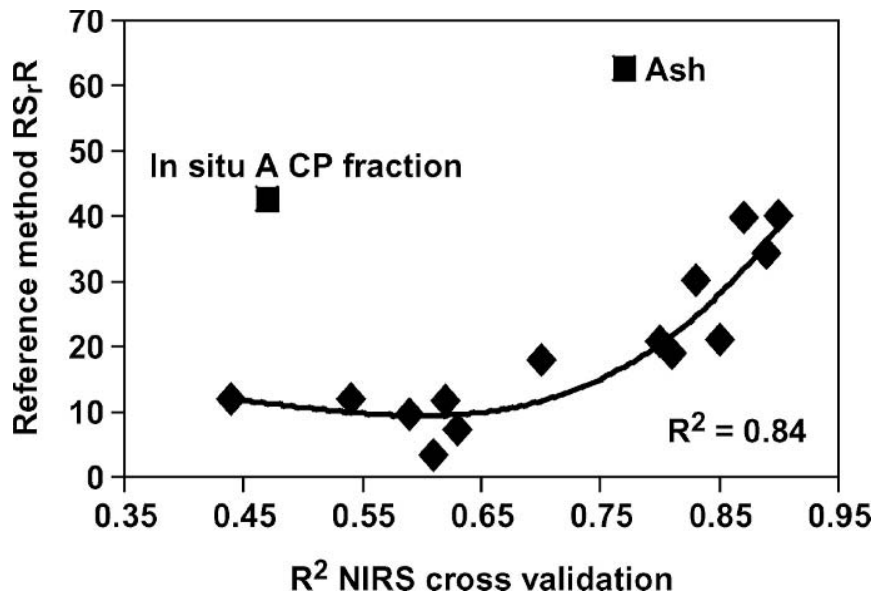

Figure 1. Relationship of reference method range to repeatability standard deviation ratio (RSrR) and coefficient of determination $\left(R^{2}\right)$ of near-infrared reflectance spectroscopy (NIRS) cross validation.

previous studies (Hruschka, 1987; Shenk and Westerhaus, 1994) with respect to reference laboratory error and NIRS predictability. Williams (1987) defined a relatively simple calculation to predict the potential of achieving an accurate NIRS equation for a given nutrient. Simply, the range of the nutrient is divided by the $\mathrm{Sr}$ of the laboratory reference method, resulting in a theoretically unitless $\mathrm{RS}_{\mathrm{r}} \mathrm{R}$ index. With a greater $\mathrm{RS}_{\mathrm{r}} \mathrm{R}$, the likelihood of achieving an accurate NIRS prediction for a given nutrient is increased. The $\mathrm{RS}_{\mathrm{r}} \mathrm{R}$ ratio for all TMR nutrients evaluated is presented in Table 1. Within the data set there is a wide span of $\mathrm{RS}_{\mathrm{r}} \mathrm{R}$, ranging from 62.8 to 3.5. To simplify this concept, the $\mathrm{RS}_{\mathrm{r}} \mathrm{R}$ is plotted against the $\mathrm{R}^{2}$ for each TMR nutrient (Figure 1). As demonstrated by Williams (1987), nutrients with low $\mathrm{RS}_{\mathrm{r}} \mathrm{R}$ were poorly predicted by NIRS and nutrients with higher $\mathrm{RS}_{\mathrm{r}} \mathrm{R}$ were better predicted by NIRS. These data suggest that failure of NIRS to predict nutrients such as TESC and IVNDFD in TMR was related to reference method error in relationship to the range for the given nutrient. Two exceptions to this summary exist, which are prediction of the in situ A CP fraction and ash in TMR by NIRS (Figure 1). In situ A and ash had relatively high $\mathrm{RS}_{\mathrm{r}} \mathrm{R}$ of 42.7 and 62.8 , respectively, but as previously explained, determination of in situ A may have been confounded by physical leakage of fine particles from the Dacron bags and may not have represented an intrinsic chemical or molecular bonding property required by NIRS to make an accurate prediction. Second, although precision of laboratory ash determination was high, ash does not have absorbance in the near-infrared reflectance spectrum (Shenk and Westerhaus, 1994). Overall, data suggest that laboratory procedures used herein for soluble $\mathrm{CP}, \mathrm{NDF} \mathrm{CP}$, in situ 
$\mathrm{A}, \mathrm{B}$, and $\mathrm{C}$ CP fractions, TESC, and IVNDFD, when conducted on TMR, were not precise enough and may have limited the ability of NIRS to make an accurate prediction for these nutrients.

A complete review of laboratory errors associated with TMR nutrients evaluated in this study would be exhaustive, but some brief comparison of our observed laboratory errors in relation to other experiments is required. First, every laboratory reference method has a measurement error that is typically defined as the standard deviation of differences between measurements of duplicate samples (Hruschka, 1987). Definitions of laboratory error vary but are often represented by terms such as laboratory error, repeatability standard deviation, reproducibility, or standard error. The literature is not standardized in the use of these definitions, and most often, the exact method of calculation is not presented. This is especially problematic when the term "standard error" is used to represent laboratory error because the standard error presented may reflect the standard error of the mean and not the laboratory standard deviation (laboratory error). Despite nuances, we can make some brief comparisons of our observed laboratory errors in reference to other literature sources. The laboratory $\mathrm{S}_{\mathrm{r}}$ observed in our study for CP, NDF, TESC, and starch were comparable to other literature references (Hruschka, 1987) or to references as they pertain directly to the assay used (Mertens, 1992; Erhman, 1996; Hall et al., 1999). Likewise, Oba and Allen (2003) reported an estimated $(\mathrm{SE} \times \sqrt{\mathrm{n}})$ laboratory error for fat $(0.4 \%)$ and ash (0.05\%) determination on corn grain, which is similar to our observed $\mathrm{Sr}$ of 0.4 and $0.1 \%$ observed for fat and ash, respectively. Laboratory error associated with 48-h in vitro digestions (idNDF, $\mathrm{S}_{\mathrm{r}}=0.7$ ) in our laboratory were similar $\left(\mathrm{S}_{\mathrm{r}}=1.07\right)$ to those reported by Mertens (1973). Because IVdOM, IVDMD, IVdNDF, and IVNDFD (\% of NDF) are all products of the same in vitro assay, laboratory error associated with these nutrients is simply the product of laboratory error associated with the in vitro incubation (idNDF) and the conutrient (e.g., OM, DM, or NDF) used in the calculation. Comparison of our observed laboratory errors associated with in situ A, B, and $\mathrm{C} \mathrm{CP}$ fractions, soluble $\mathrm{CP}$ and NDF CP determinations with other reports is difficult due either to a lack of references or, in the case of in situ CP fraction determination, widely varying methods. We cannot conclude that our laboratory procedures achieved maximum precision for a TMR given nutrient, but can conclude that intrinsic laboratory error associated with reference method procedures used in our study appear similar to laboratory errors observed in previous reports.

Finally, simple laboratory error of reference chemistry methods may not explain all of the factors associated with poor NIRS prediction of soluble $\mathrm{CP}$, NDF CP, in situ A, B, and C CP fractions, TESC, and IVNDFD in this study. Predicting these nutrients in a heterogeneous TMR compared with prediction in a relatively homogeneous material such as forage may result in heterogeneous absorbance, making relationships between absorbance and the nutrient of interest more challenging. In addition, the complexities of organic bonds that relate to a digestive process are logically more complex than organic bonds associated with more straightforward molecules such as protein or starch. Because organic bonds absorb light in the NIRS region, the complexity of absorption may relate to the complexities of predicting a given nutrient. Defining these possible errors associated with NIRS prediction of soluble CP, NDF CP, in situ A, B, and C CP fractions, TESC, and IVNDFD in TMR were beyond the scope of this study but cannot be discounted as sources of error in NIRS prediction of a nutrient.

\section{CONCLUSIONS}

This study, which evaluated the utility of NIRS to predict chemical and biological nutrients in TMR, was conducted to assess technical aspects of currently available commercial programs that evaluate nutrients in TMR using NIRS. We observed NIRS to have good utility in predicting basic nutrients such as CP, NDF, starch, NFC, and fat in TMR. Developing NIRS equations to predict these nutrients in TMR could be used to monitor mixing and basic aspects of TMR formulations. However, difficulty was observed in predicting key biological nutrients, such as in situ protein fractions and IVNDFD in TMR using NIRS, which appeared to be related to reference method error in relationship to the range of nutrient values available. If NIRS prediction of these nutrients were sought, more precise laboratory procedures or multiple laboratory replications would likely be required to achieve acceptable NIRS predictions.

\section{REFERENCES}

Almendingen, K., H. M. Meltzer, J. I. Pedersen, B. N. Nilsen, and M. Ellekjaer. 2000. Near infrared spectroscopy - a potentially useful method for rapid determination of fat and protein content in homogenized diets. Eur. J. Clin. Nutr. 54:20-23.

AOAC. 1990. Official Methods of Analysis. 15th ed. Association of Official Analytical Chemists, Arlington, VA.

Aufrere, J., and B. Michalet-Doreau. 1988. Comparison of methods for predicting digestibility of feeds. Anim. Feed Sci. Technol. 20:203-218.

Barriere, Y., G. Dias Goncalves, J. C. Emile, and B. Lefevre. 2004. Higher intake of DK265 corn silage by dairy cattle. J. Dairy Sci. 87:1439-1445.

Brehm, N. M., P. C. Hoffman, J. B. Peters, D. K. Combs, and D. J. Undersander. 1997. Estimation of crude protein and microbial 
protein contamination of in situ forage residues by near infrared spectroscopy. J. Dairy Sci. 80(Suppl. 1):217. (Abstr.)

Cherney, D. J., J. A. Patterson, and R. P. Lemenager. 1990. Influence of in situ bag rinsing technique on determination of dry matter disappearance. J. Dairy Sci. 73:391-397.

Dorshorst, M. E., and P. C. Hoffman. 2000. Short communication: A novel system to estimate protein degradability in legume and grass hays. J. Dairy Sci. 83:1503-1504.

Ehrman, T. 1996. Determination of starch in biomass samples by chemical solubilization and enzymatic digestion. LAP-016. U.S. Dept. of Energy. Natl. Bioenergy Center, Washington, DC.

Goering, H. K., and P. J. Van Soest. 1970. Forage Fiber Analyses (Apparatus, Reagents, Procedures, and Some Applications). Agric. Handbook No. 379. ARS-USDA, Washington, DC.

Grant, R. J., and D. R. Mertens. 1992. Impact of in vitro fermentation techniques upon kinetics of fiber digestion. J. Dairy Sci. 75:1263-1272.

Grant, R. J., and S. J. Weidner. 1992. Digestion kinetics of fiber: Influence of in vitro buffer $\mathrm{pH}$ varied within observed physiological range. J. Dairy Sci. 75:1060-1068.

Hall, M. B., W. H. Hoover, J. P. Jennings, and T. K. Miller Webster. 1999. A method for partitioning neutral detergent-soluble carbohydrates. J. Sci. Food Agric. 79:2079-2086.

Hoffman, P. C., N. M. Brehm, L. M. Bauman, J. B. Peters, and D. J. Undersander. 1999. Prediction of laboratory and in situ protein fractions in legume and grass silages using near-infrared reflectance spectroscopy. J. Dairy Sci. 82:764-770.

Hruschka, W. R. 1987. Data analysis: Wavelength selection methods. Pages 35-53 in Near-infrared Technology in the Agricultural and Food Industries. Amer. Assoc. Cereal Chem., St. Paul, MN.

Jung, H. G., Mertens, D. R., and Buxton, D. R. 1998. Forage quality variation among maize inbreeds: In vitro fiber digestion kinetics and prediction with NIRS. Crop Sci. 38:205-210.

Krishnamoorthy, V., C. J. Sniffen, M. D. Stern, and P. J. Van Soest. 1983. Evaluation of a rumen mathematical model and in vitro simulated proteolysis to estimate the undegraded dietary nitrogen content of the feedstuff. Br. J. Nutr. 50:555-564.

Lundberg, K. M., P. C. Hoffman, L. M. Bauman, and P. Berzaghi. 2004. Prediction of forage energy content by near infrared reflectance spectroscopy and summative equations. Prof. Anim. Sci. 20:262-269.
Marten, G. C., J. C. Halgerson, and J. H. Cherney. 1983. Quality prediction of small grain forages by near infrared reflectance spectroscopy. Crop Sci. 23:94-101.

Marten, N. P., and J. G. Linn. 1989. Extension applications in NIRS technology transfer. Pages 48-53 in Near Infrared Reflectance Spectroscopy (NIRS): Analysis of Forage Quality. USDA Agric. Handbook No. 643. Washington, DC.

Mertens, D. R. 1973. Application of theoretical mathematical models to cell wall digestion and forage intake in ruminants. Ph.D. Thesis. Cornell University, Ithaca, NY.

Mertens, D. R. 1992. Critical conditions in determining detergent fibers. Page C-1 in Proc. Natl. Forage Testing Assoc. Forage Anal. Workshop, Denver, CO. Natl. Forage Testing Assoc., Omaha, NE.

Narra, S., T. W. Fermanian, and J. M. Swiader. 2005. Analysis of mono- and polysaccarides in creeping bentgrass turf using near infrared reflectance spectroscopy. Crop Sci. 45:266-273.

National Research Council. 2001. Nutrient Requirements of Dairy Cattle. 7th rev. ed. Natl. Acad. Sci., Washington, DC.

Nocek, J. E. 1988. In situ and other methods to estimate ruminal protein and energy digestibility: A review. J. Dairy Sci. 71:2051-2067.

Norris, K. H., R. F. Barnes, J. E. Moore, and J. S. Shenk. 1976 Predicting forage quality by infrared reflectance spectroscopy. J. Anim. Sci. 43:889-897.

Oba, M., and M. S. Allen. 2003. Effects of corn grain conservation method on ruminal digestion kinetics for lactating dairy cows at two dietary starch concentrations. J. Dairy Sci. 86:184-194.

Shenk, J. S., and M. O. Westerhaus. 1991a. Infrasoft International Software for Near Infrared Instruments. NIR Systems, Inc., Silver Spring, MD.

Shenk, J. S., and M. O. Westerhaus. 1991b. Population definition, sample selection, and calibration procedures for near infrared reflectance spectroscopy. Crop Sci. 31:469-474.

Shenk, J. S., and M. O. Westerhaus. 1994. The application of near infrared reflectance spectroscopy (NIRS) to forage analysis. Pages 406-499 in Forage Quality Evaluation and Utilization. Am. Soc. Agron., Madison, WI.

White, M., and K. Rouvinen-Watt. 2004. Near-infrared evaluation of wet mink diets. Anim. Feed Sci. Technol. 111:239-246.

Williams, P. C. 1987. Variables affecting near-infrared reflectance spectroscopic analysis. Pages 143-168 in Near-infrared Technology in the Agricultural and Food Industries. Am. Assoc. Cereal Chem., St Paul, MN. 